\title{
Naturally Occurring Microbiota Associated with Mosquito Breeding Habitats and Potential Parasitic Species against Mosquito Larvae: A Study from Gampaha District, Sri Lanka
}

\author{
H. A. K. Ranasinghe $(1)$ and L. D. Amarasinghe \\ Department of Zoology and Environmental Management, Faculty of Science, University of Kelaniya, Dalugama, Kelaniya, Sri Lanka \\ GQ 11600 \\ Correspondence should be addressed to L. D. Amarasinghe; deepika@kln.ac.lk
}

Received 6 February 2020; Revised 19 March 2020; Accepted 8 April 2020; Published 28 April 2020

Academic Editor: Stephen Munga

Copyright ( $\odot 2020$ H. A. K. Ranasinghe and L. D. Amarasinghe. This is an open access article distributed under the Creative Commons Attribution License, which permits unrestricted use, distribution, and reproduction in any medium, provided the original work is properly cited.

\begin{abstract}
A mosquito species has its own favourable requirements of abiotic and biotic characteristics including microbiota, in a breeding habitat. Some of the microbiota may cause parasitic or pathogenic effects to mosquito larvae such as species of viruses, parasitic bacteria, fungi, protists, entomopathogenic nematodes, and filamentous fungi. In Sri Lanka, there is a scarcity of information on microbiota associated with mosquito breeding habitats and their effect on mosquito larvae. Hence, the present study was conducted to determine microbiota species/taxa associated with a variety of mosquito breeding habitats in selected areas of the Gampaha District in Sri Lanka and the relationship, if any, the microbiota has with mosquito larva survival and breeding. Fortyfive microbiota species belonging to 11 phyla were found from different mosquito breeding habitats with the highest percentage belonging to phylum Euglenozoa (27.89\%). Species that belonged to the phylum Amoebozoa (1.22\%) and Sarcodina (1.17\%) had the lowest abundance, and each of its species richness was recorded as one. Philodina citrina followed by Monostyla bulla comprised $30.8 \%$ and $16.59 \%$, respectively, of the total rotifer population. From the total microbiota, 25-50\% existed as accidental while less than $25 \%$ rare, in the habitat type according to their abundance. Paddy fields had the highest species richness (17), evenness (23.52), Shannon-Weiner (66.64), and beta diversity (0.65) over 50\% indicating high heterogeneity in microbiota composition among the habitats. Ciliated protists, namely, Vorticella microstoma, Zoothamnium spp., and Chilodinella sp., were identified as naturally occurring microbiota associated with Culex mosquito larvae that inhabited in paddy fields and associated irrigation canals. Only Vorticella microstoma caused a significant lethal effect on mosquito larvae. This study revealed that species of $C x$. gelidus, Cx. pseudovishnui, Cx. tritaeniorhynchus, Cx. quinquefasciatus, and Cx. whitmorei served as hosts for $V$. microstoma where infectivity rate in $C x$. tritaeniorhynchus reached 73.22. Chilodinella sp. selectively served as endoparasitic to $C x$. gelidus larvae causing only $4.58 \%$ mortality, and invasive cysts of the pathogen were observed in the subcuticular layer of the host body. Even though Zoothamnium spp. were found on Cx. tritaeniorhynchus larvae, there was no lethal effect due to the attachment of the parasitic agent. The potential of these microbiotas in integrated vector controlling approaches in future perspectives is recommended.
\end{abstract}

\section{Introduction}

Distribution, abundance, and individual fitness of mosquito immatures in a particular breeding habitat are known to be dependent on mainly three factors: biotic [1,2], abiotic [3-5], and their interaction between each other and with other associated taxa $[6,7]$. When there is coexistence or mutualism of different mosquito species along with other biotic organisms, they form a community sharing habitat requirements [8]. There are "competitors" of mosquitoes such as algae, bacteria, detritus, and protists that feed upon the same functional food as mosquito larvae in the same habitat [9]. Controphic competitors cause a negative impact on mosquito larval populations. Further, there is an interspecific 
resource competition under food-limiting environments when multiple mosquito species present simultaneously within the same mosquito breeding habitats [10]. Competitors of mosquito larvae included cladocerans and copepods such as calanoids and harpacticoids [11, 12]. Naturally occurring microcrustaceans could be used as effective competitors against mosquito larvae because many species show similar biotope preferences with mosquito larvae such as early colonization of temporary ponds and filter feeding behavior [13]. Competitors and predators can reduce the survival of mosquitoes either by competing for the same food resources or preying on mosquito larvae. Thus, the interaction of competition and predation of many other invertebrate taxa such as Crustacea, Acaria, and insect larvae who share the same habitats with mosquito larvae is another factor determining the abundance of mosquito larvae in a particular habitat $[14,15]$. The major controphic competitors such as cladocerans and ostracods exhibit polyphagous activities with larvae and an effect on their abundance in breeding habitats. Cladocerans are the dominant microinvertebrate which coinhabit with mosquito larvae and other zooplankton communities in rock pools [16]. However, ostracods act as both food competitors and predators of mosquito larvae while copepods act as omnivorous filter feeders which consume mostly large-sized food particles [17]. There are only very few studies and scattered information focused on microbiota association with mosquito larvae in Sri Lanka [18, 19]. Simultaneously, there is a need to develop biopesticides against vector mosquito larvae as a useful substitute to chemical insecticides. In this contest, information on microbiota species association with vector mosquito breeding habitats as potential parasitic or pathogenic species against mosquito immature stages in Sri Lanka should be further studied. Therefore, the present study was conducted to identify naturally occurring microbiota species associated with a variety of vector mosquito breeding habitats and to identify potential parasitic or pathogenic microbiota on mosquito larvae under the natural environment.

\section{Methodology}

2.1. Study Area. Gampaha District is located in the west of Sri Lanka and has an area of 1,387 square kilometers. It is bounded by Kurunegala and Puttalam districts from the north, Kegalle District from the east, Colombo District from the south, and the Indian Ocean from the west. The climate is tropical in the Gampaha District with a significant rainfall even in the driest months. The average annual temperature in Gampaha is $27.3^{\circ} \mathrm{C}$. In a year, the average rainfall is $2398 \mathrm{~mm}$.

2.2. Sampling of Mosquito Breeding Habitats for Microbiota and Mosquito Larvae. Forty mosquito breeding sites were selected within the district randomly, and each sampling site was georeferenced (GARMIN-etrex SUMMIT) (Figure 1). Water samples from each site were collected using a standard $250 \mathrm{~mL}$ dipper bimonthly from September 2017 to August 2018. When dipping is impossible, sampling was performed using pipetting or siphoning methods (maximum $250 \mathrm{~mL}$ ) into a larval rearing container (height $12 \mathrm{~cm} \times$ diameter $6.5 \mathrm{~cm}$ ). Five to eight numbers of mature larvae in a water sample were carefully separated at the site, into a glass vial with $70 \%$ ethanol, by using a pipette and labeled for mosquito species identification, and larvae in each sample were identified into species level using standard identification keys [20-22] in the laboratory.

A water sample was then transferred equally into three plastic containers $(6.5 \mathrm{~cm}$ width, $12 \mathrm{~cm}$ height). Two of them were immediately preserved separately in Rose Bengal stain (5\% formalin with $0.04 \%$ Rose Bengal stain) solution and 5\% Lugols' solution for microbiota identification. The remaining sample was kept as nonpreserved and covered with a small-sized mesh net for live observations. All samples were labeled and transferred carefully into the laboratory for further processing.

2.3. Identification of Microbiota. One $\mathrm{mL}$ aliquot of the preserved sample was examined under a compound microscope (×100 magnification) (OLYMPUS x C21) using a Sedgwick Rafter (S-R) cell (50 mm length, $20 \mathrm{~mm}$ width, and $1 \mathrm{~mm}$ deep) and HYDRO-BIOS phytoplankton chamber (dimensions, $33 \times 33 \mathrm{~mm}$; thickness, $1 \mathrm{~mL}$ ) for quantifying the microbiota. The sample was well shaken before taking the aliquot for observation. Microbiota species/taxa were recorded, and identification was done to taxa/species level using temporary slide mounts observed under ( $\times 400$ magnification) using standard identification keys [23-25].

2.4. Microbiota Interaction with Mosquito Larvae. Each nonpreserved sample was observed microscopically in a regular manner in the laboratory for microbiota interaction with mosquito larvae until the pupation of mosquito larvae and any observations were recorded.

2.5. Data Analysis. Occurrence frequencies of microbiota species were categorized as constant for species found in more than $50 \%$ of the collections, common when found between $25 \%$ and $50 \%$ of the collections, and accidental or rare species when found in less than $25 \%$ of the collections [26]. Microbiota alpha diversity $(\alpha)$ was calculated for each breeding habitat type as the total number of species in the sampling periods. $\alpha$ medium was calculated as the average between the $\alpha$ diversity for the system of the same type; gamma diversity $(\mathcal{Y})$ was estimated using the total number of species from all samples.

Beta diversity $(\beta)$ was estimated by measuring the species turnover using the $\beta-1$ index [27], measures the amount that regional diversity exceeds mean alpha diversity, and is calculated by the formula $\beta-1=[(S / \alpha$ mean $)-1] /[N-1] \times$ 100 , where $S$ is the regional diversity or total richness (the number of species per each sampling site); $\alpha$ mean is the mean alpha diversity (mean number of species) for each site in each period; and $N$ is the number of sites of the period. Beta diversity over $50 \%$ indicates high heterogeneity in microbiota composition among systems; between 20 and 50\% indicates intermediate heterogeneity; and below $20 \%$ indicates low heterogeneity $[27,28]$. 


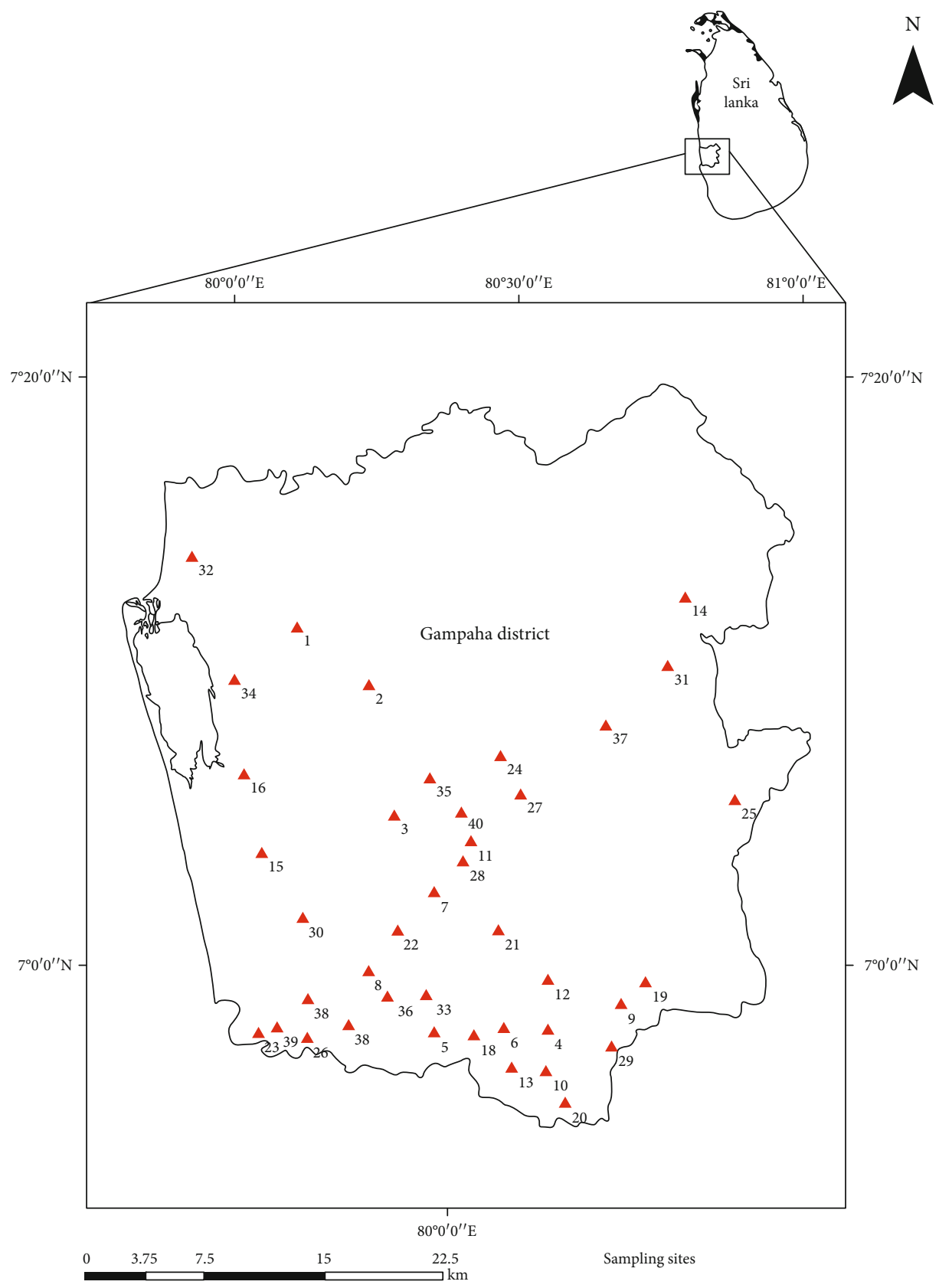

FIGURE 1: Sampling locations from the selected study site; Gampaha District.

The microbiota species diversity was also estimated according to the indices of Shannon and Weaver [29] and evenness [30].

$$
\text { Shannon Index }(H)=-\sum_{i=1}^{s} p_{i} \ln p_{i}
$$

In the Shannon index, $p$ is the proportion $(n / N)$ of individuals of one particular species found $(n)$ divided by the total number of individuals found $(N), \ln$ is the natural $\log$, $\Sigma$ is the sum of the calculations, and $s$ is the number of species.
Pielou's evenness $(J)$

$$
J=\frac{H^{\prime}}{H_{\max }}
$$

compares the Shannon-Wiener diversity value $\left(H^{\prime}\right)$ to the maximum possible diversity value $\left(H_{\max }\right)$.

\section{Results}

3.1. Diversity and Occurrence of Mosquito and Microbiota Species. During the study, ten mosquito species from twelve different types of habitats (Figure 2) (paddy fields $(n=6)$, 


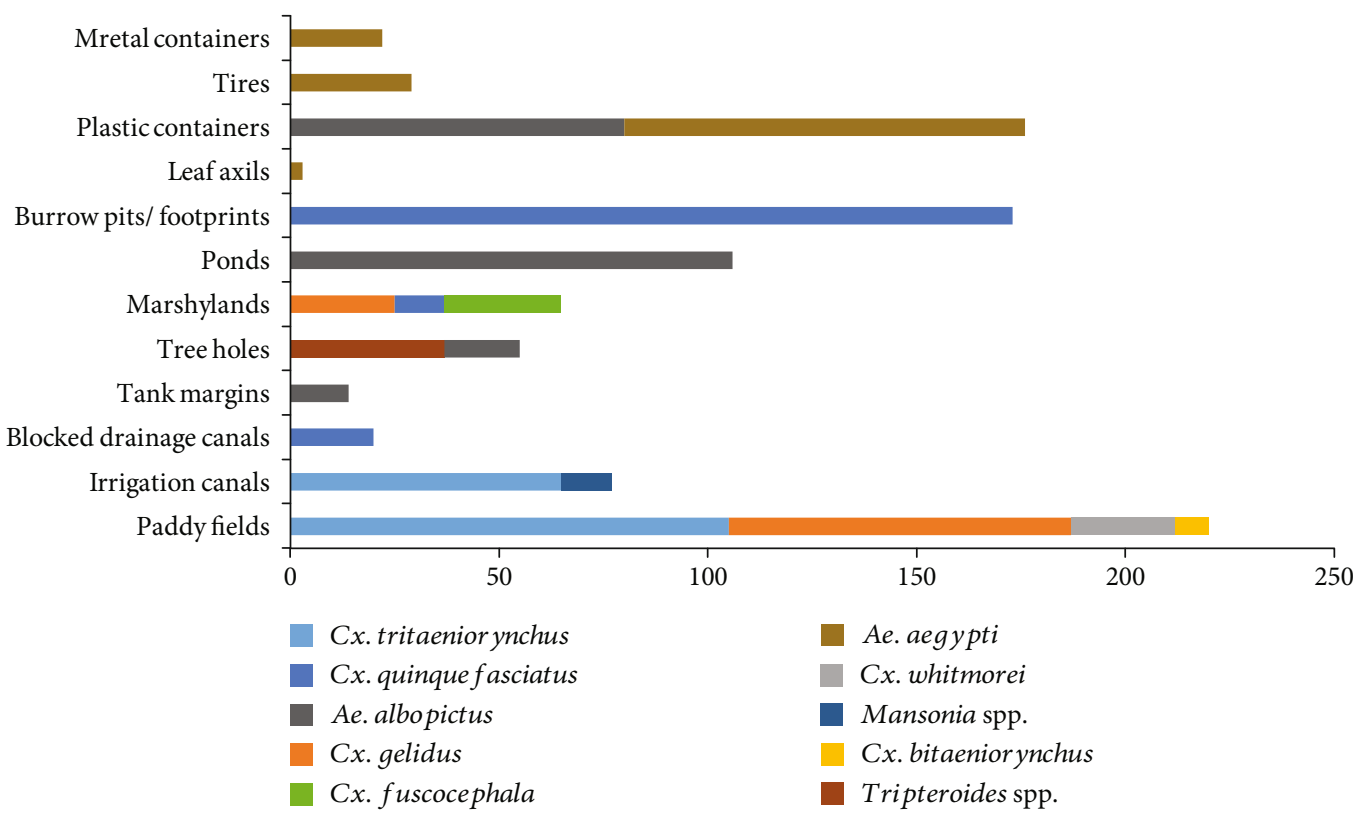

Figure 2: The abundance of mosquito larvae in mosquito breeding habitats from the Gampaha District.

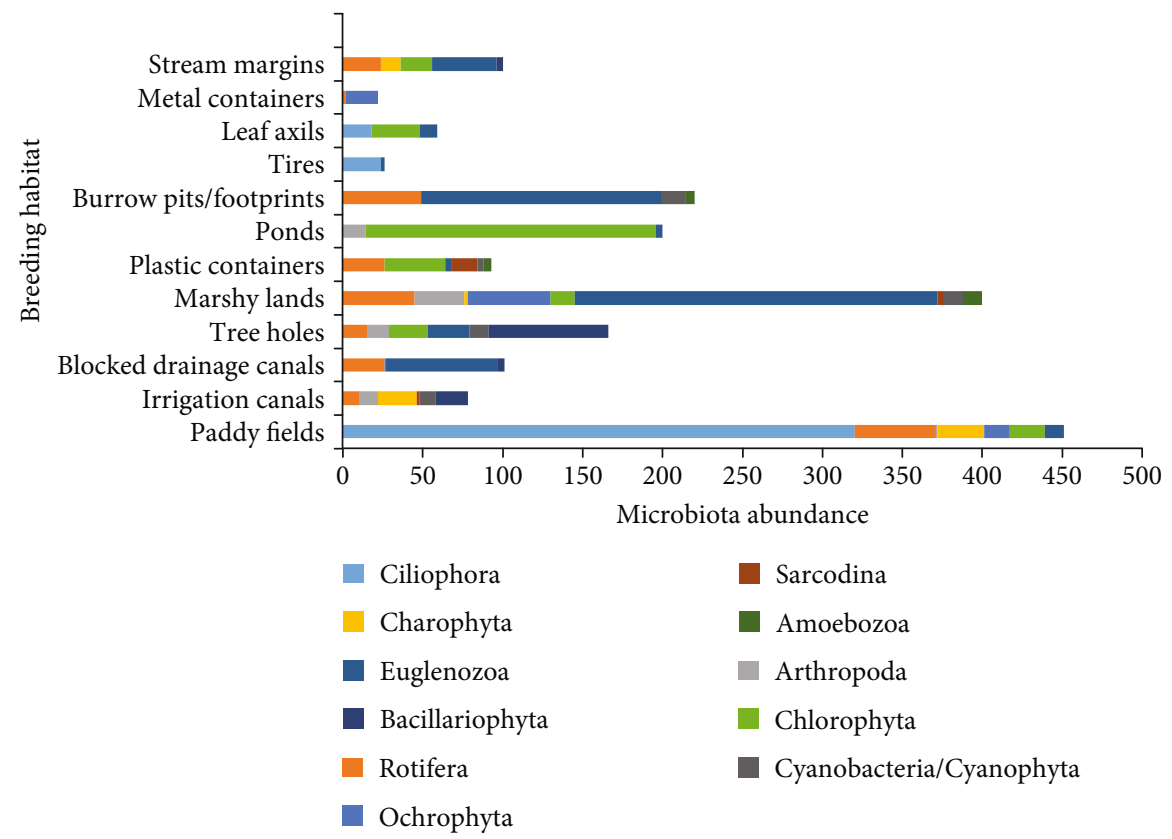

FIgURE 3: Occurrence of microbiota phyla encountered from different mosquito breeding habitats.

irrigation canals $(n=3)$, blocked drainages $(n=1)$, marshy lands $(n=4)$, tree holes $(n=3)$, tank margins $(n=1)$, plastic containers $(n=2)$, burrow pits/footprints $(n=3)$, ponds $(n=1)$, leaf axils $(n=1)$, used tires $(n=1)$, and metal containers $(n=1)$ were encountered. Six permanent macrotype mosquito breeding habitats, namely, paddy/rice fields, irrigation canals, blocked drainages, marshy lands, ponds, and tank margins, and six temporary microtype mosquito breeding habitats, namely, tree holes, plastic containers, burrow pits/footprints, metal containers, discarded tires, and leaf axils, were found across the study area Aedes aegypti and Aedes albopictus which were dengue vector mosquitoes in
Sri Lanka were prominently found from plastic and metal container habitats while four Culex species (Culex bitaeniorhynchus, Culex tritaeniorhynchus, Culex gelidus, and Culex whitmorei) were found from rice fields. The highest mosquito abundance was recorded from rice fields.

A total number of 45 microbiota species belong to 11 phyla, namely, Amoebozoa, Arthropoda, Bacillariophyta, Ciliophora, Charophyta, Chlorophyta, Protista, Cyanobacteria/Cyanophyta, Euglenozoa, Ochrophyta/Heterokontophyta, and Rotifera, were recorded from different mosquito breeding habitats (Figure 3). The highest percentage abundance was recorded from members of the phylum Euglenozoa 


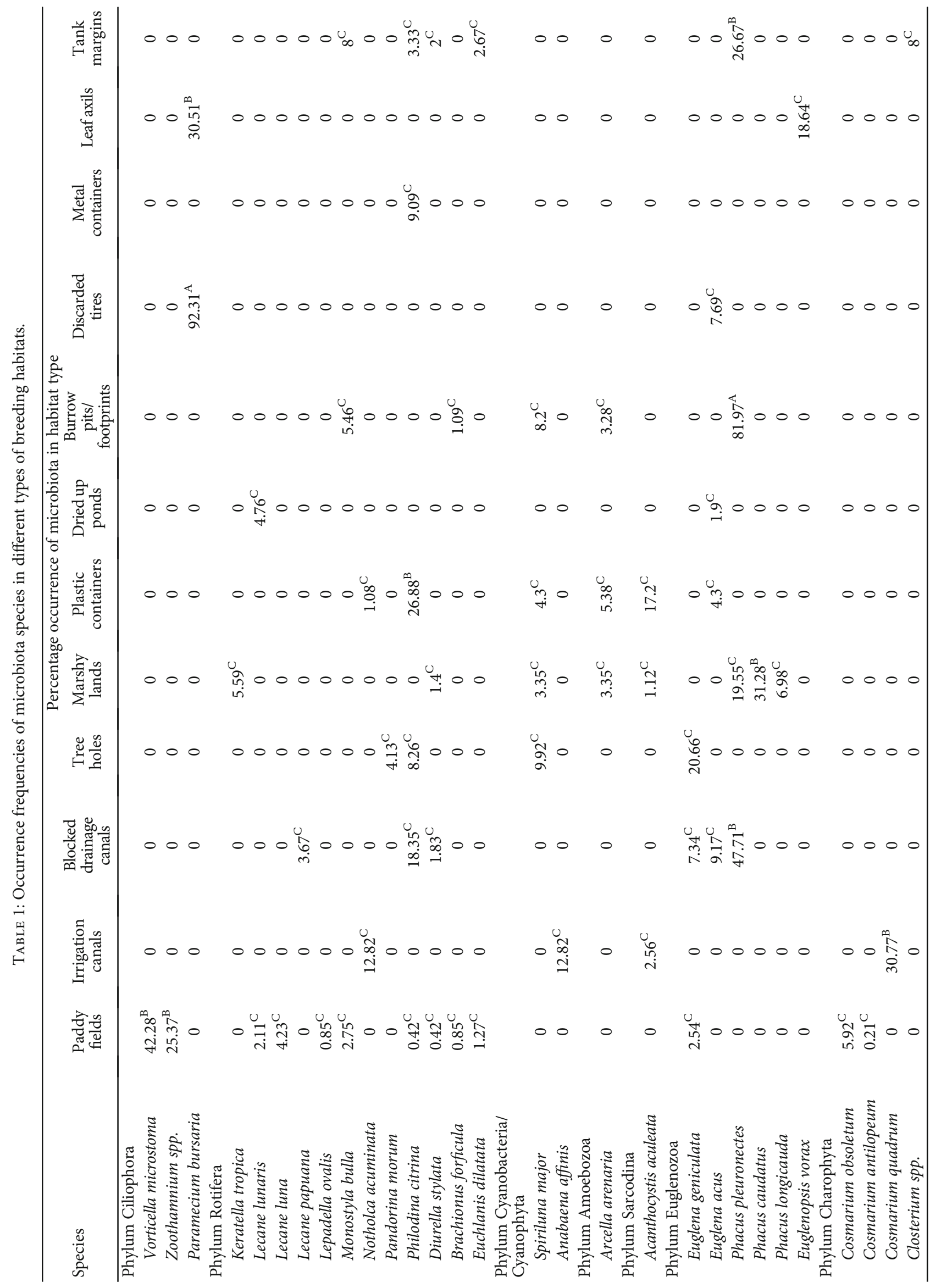




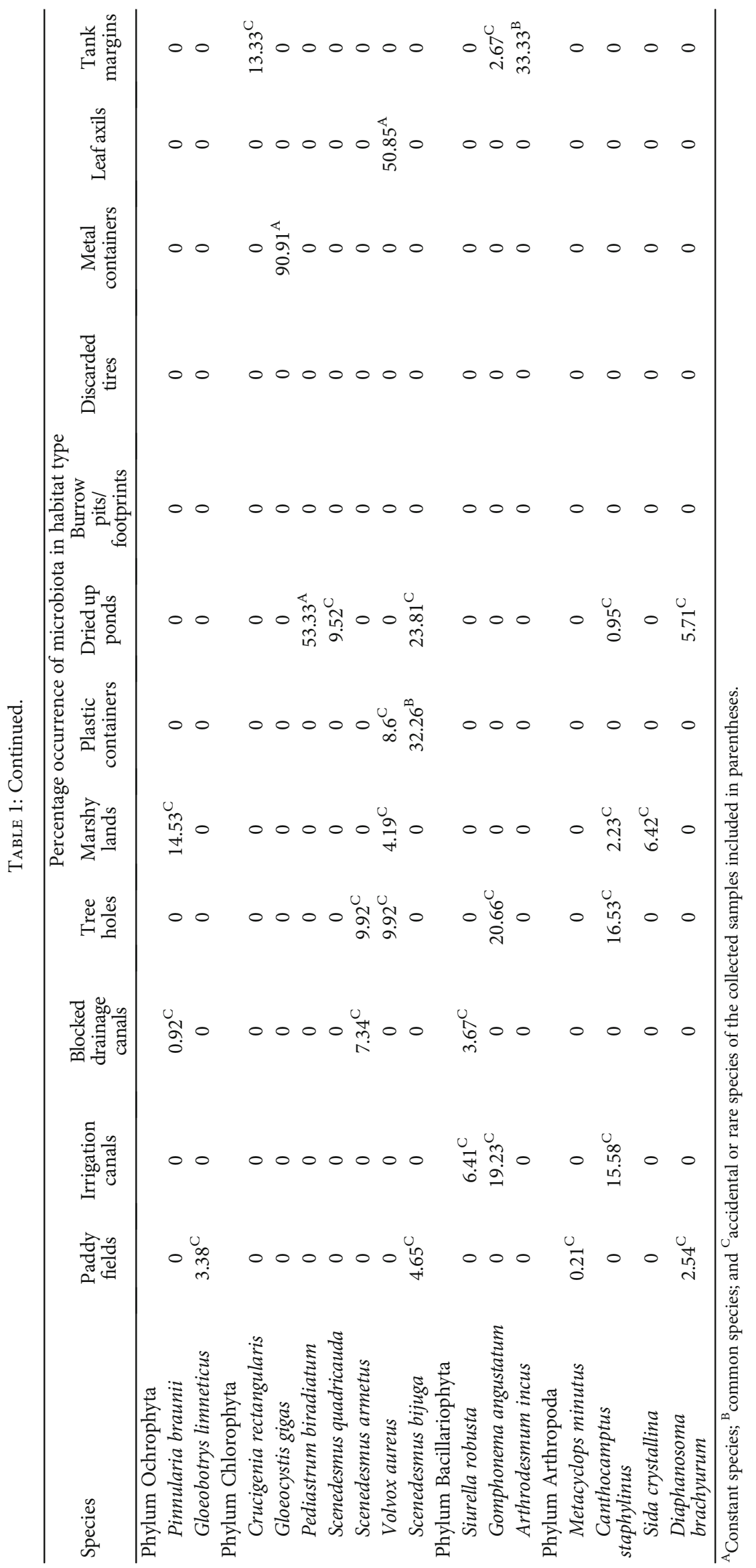




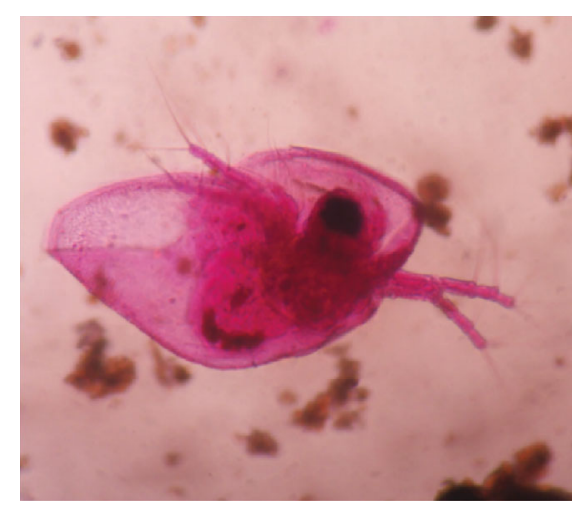

(a)

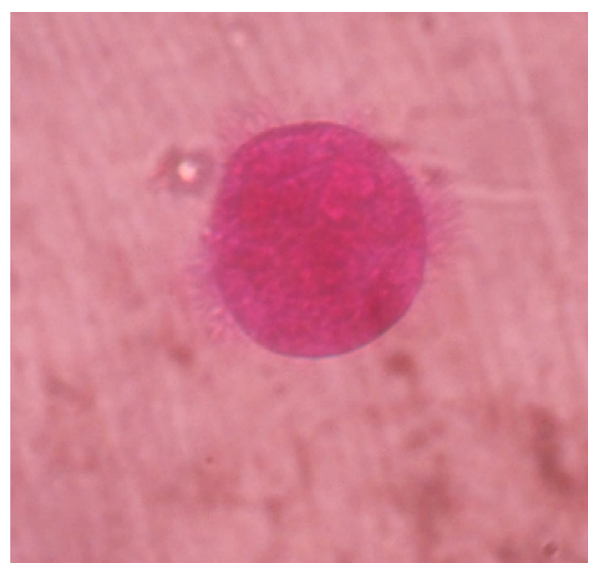

(d)

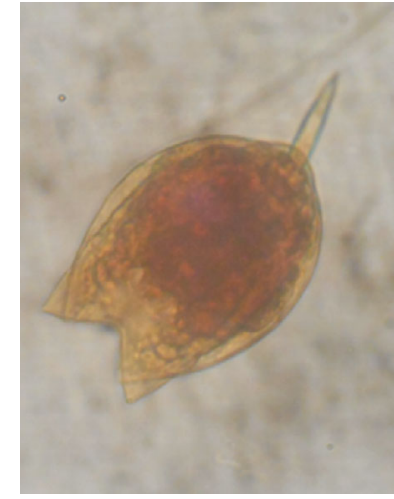

(b)

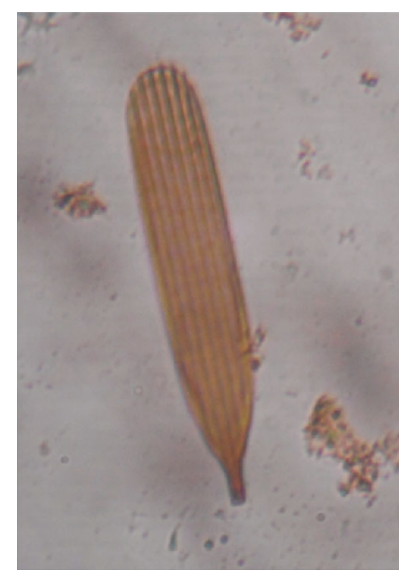

(e)

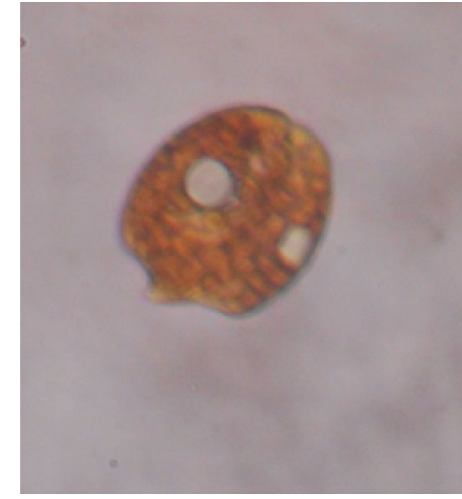

(c)

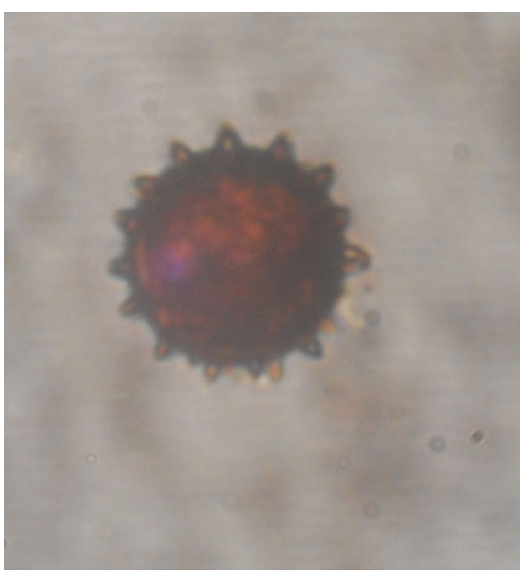

(f)

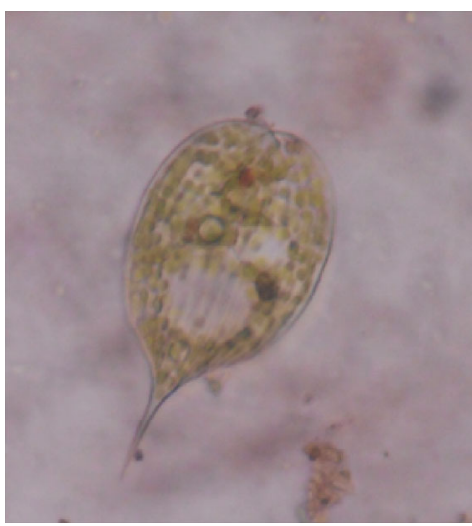

(h)

FIgURE 4: Microscopic view of some microbiota species encountered from mosquito breeding habitats, $\times 400$ magnification (a) Sida crystallina, (b) Lecane luna, (c) Phacus pleuronectes, (d) Acanthocystis aculeata, (e) Notholca acuminata, (f) Volvox aureus, (g) Closterium sp., and (h) Phacus longicauda.

(27.89\% of total microbiota) while the highest number of species was recorded from members of phylum Rotifera (Table 1). Among them, Philodina citrina followed by Monostyla bulla comprised $30.8 \%$ and $16.59 \%$, respectively, of the total rotifer population. They exhibited a very wide range of morphological variations (Figure 4). Species of the phylum Amoebozoa and Sarcodina had the lowest abundance, and each of its species richness was recorded as one. Phacus pleuronectes (81.97\%) in burrow pits/footprints, Gloeocystis gigas (90.91\%) in a metal container, Paramecium bursaria (92.31\%) in discarded tires, Volvox aureus in leaf axils (50.85\%), and Pediastrum biradiatum (53.33\%) in ponds existed as constant species in the particular breeding habitat (Table 2). Vorticella microstoma (42.28\%) and Zoothamnium spp. (25.37\%) existed as common species in paddy fields. Cosmarium quadricauda (30.77\%) in irrigation canals, Phacus pleuronectes (47.71\%) in blocked drainages, Phacus caudatus (31.38\%) in marshy lands, and Paramecium bursaria (30.51\%) in leaf axils also existed as common species. Additionally, plastic containers (Philodina citrina 
TABLE 2: Evenness, Shannon diversity, alpha $(\alpha)$, alpha medium, and beta $(\beta)$ and gamma $(\gamma)$ diversities of type of habitats.

\begin{tabular}{|c|c|c|c|c|c|c|}
\hline Habitat & $\begin{array}{l}\text { Alpha } \\
\text { diversity }\end{array}$ & $\begin{array}{l}\text { Alpha } \\
\text { medium } \\
\text { diversity }\end{array}$ & $\begin{array}{c}\text { Beta } \\
\text { diversity }\end{array}$ & $\begin{array}{l}\text { Gamma } \\
\text { diversity }\end{array}$ & $\begin{array}{l}\text { Shannon-Weiner } \\
\text { diversity index }\end{array}$ & Evenness \\
\hline \multirow{6}{*}{ Paddy fields } & 9 & 4 & 0.65 & 17 & 66.64 & 23.52 \\
\hline & 5 & & & & & \\
\hline & 3 & & & & & \\
\hline & 4 & & & & & \\
\hline & 1 & & & & & \\
\hline & 4 & & & & & \\
\hline \multirow{3}{*}{ Irrigation canals } & 4 & 4 & 0.38 & 7 & 15.22 & 7.82 \\
\hline & 4 & & & & & \\
\hline & 3 & & & & & \\
\hline Blocked drainages & 9 & 9 & 0 & 9 & 25.35 & 11.54 \\
\hline \multirow{3}{*}{ Tree holes } & 5 & 5 & 0.3 & 8 & 17.57 & 8.45 \\
\hline & 8 & & & & & \\
\hline & 3 & & & & & \\
\hline \multirow{4}{*}{ Marshy lands } & 7 & 5 & 0.47 & 12 & 35.55 & 14.31 \\
\hline & 8 & & & & & \\
\hline & 5 & & & & & \\
\hline & 1 & & & & & \\
\hline \multirow{5}{*}{ Plastic containers } & 3 & 2 & 0.75 & 8 & 20.41 & 9.82 \\
\hline & 2 & & & & & \\
\hline & 4 & & & & & \\
\hline & 1 & & & & & \\
\hline & 1 & & & & & \\
\hline Ponds & 8 & 8 & 0 & 8 & 18.94 & 9.11 \\
\hline \multirow{3}{*}{$\begin{array}{l}\text { Burrow } \\
\text { pits/footprints }\end{array}$} & 3 & 2 & 0.75 & 5 & 13.54 & 8.41 \\
\hline & 1 & & & & & \\
\hline & 3 & & & & & \\
\hline \multirow{2}{*}{ Metal containers } & 2 & 2 & 0 & 2 & 2.49 & 3.59 \\
\hline & 2 & & & & & \\
\hline Leaf axils & 3 & 3 & 0 & 3 & 3.54 & 3.22 \\
\hline Tires & 2 & 2 & 0 & 2 & 2.64 & 3.81 \\
\hline Tank margins & 9 & 9 & 0 & 9 & 24.05 & 10.95 \\
\hline
\end{tabular}

TABle 3: Number of mosquito larvae examined and recorded as naturally infested with $V$. microstoma in paddy fields and associated irrigation canals.

\begin{tabular}{lcccccc}
\hline $\begin{array}{l}\text { Habitat type } \\
\text { searched }\end{array}$ & Cx. bitaenyorhynchus & Cx. tritaeniorhynchus & Cx. gelidus & Cx. quinquefasciatus & Cx. whitmorei & Cx. pseudovishnui \\
\hline $\begin{array}{l}\text { Paddy fields } \\
\begin{array}{l}\text { Irrigation } \\
\text { canals }\end{array}\end{array}$ & $0 / 451=0$ & $186 / 254=73.22 \%$ & $143 / 289=49.48 \%$ & $40 / 108=37.04 \%$ & 0 & $120 / 485=24.74 \%$ \\
\end{tabular}

26.88\%, Scenedesmus bijuga 32.26\%) and stream margins (Phacus pleuronectes 26.7\%, Arthrodesmum incus 33.33\%) had two common microbiota species in each of their habitats. However, the majority of the microbiota existed as accidental or rare species in the habitat type according to their abundance (Table 2).

Species richness of the microbiota was highest in paddy fields (Table 2; gamma diversity, $\gamma$ ). Paddy fields had the 


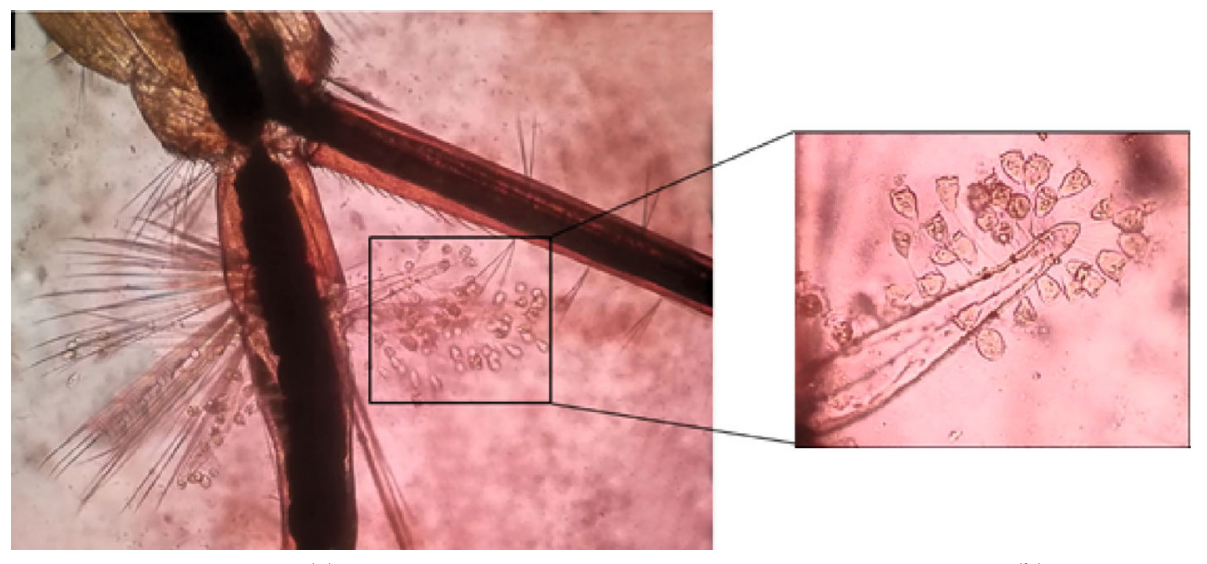

(a)

(b)

Figure 5: (a) Infestation of V. microstoma to $3^{\text {rd }}$ instar larva of $C x$. pseudovishnui anal papillae region (x40 magnification); (b) attached trophonts of $V$. microstoma (x100 magnification).

highest beta diversity over 50\% indicating high heterogeneity in microbiota composition among the systems. Irrigation canals, tree holes, marshy lands, plastic containers, and burrow pits/footprints had beta diversity between $20 \%$ and $50 \%$, indicating intermediate heterogeneity in microbiota composition among the systems. Blocked drainages, ponds, metal containers, leaf axils, tires, and tank margins had a beta diversity below 20\%, indicating low heterogeneity. Paddy fields resulted the highest Shannon-Weiner diversity index and evenness values.

3.2. Parasitic or Pathogenic Microbiota. During the time natural population of mosquito larvae is kept under regular check in the laboratory, unusual high mortalities were observed in Cx. tritaeniorhynchus mosquito larvae collected from a paddy field which prompted to detect the causative organism. A peritrich ciliate, Vorticella microstoma (Identification key [24]), was found attached to the body of such dead larvae.

Five species of Culex mosquito larvae $(n=1587)$ collected from paddy fields $(n=24)$ and associated irrigation canals $(n=10)$ were resulted with varying degrees of V. microstoma infestation under natural environmental conditions and are shown in Table 3. Out of the total collection of Culex mosquito larvae, $47.07 \%(n=747)$ were positive for $V$. microstoma infestation (Figures 5(a) and 5(b)). The infectivity rate (percentage of larvae infested with $V$. microstoma) of $C x$. tritaeniorhynchus was higher compared with that of the other Culex species, which comprised $73.22 \%$ of the total collection (Table 3). During the study, Cx. quinquefasciatus larvae were found associated in abandoned paddy fields where the parasitic species was not usually detected. However, only 40 out of 108 (37.04\%) were found to harbor V. microstoma, indicating relatively a low larval susceptibility to ciliate infection compared to other vulnerable Culex species (Table 3).

Zoothamnium sp. was recorded as parasitic on Cx. gelidus mosquito larvae (Figure 6) in this study but observations did not support for its lethal effect on mosquito larvae. Zoothamnium sp. has one main stalk with many branches ending in zooids, which is the distinct morphological feature to distin-

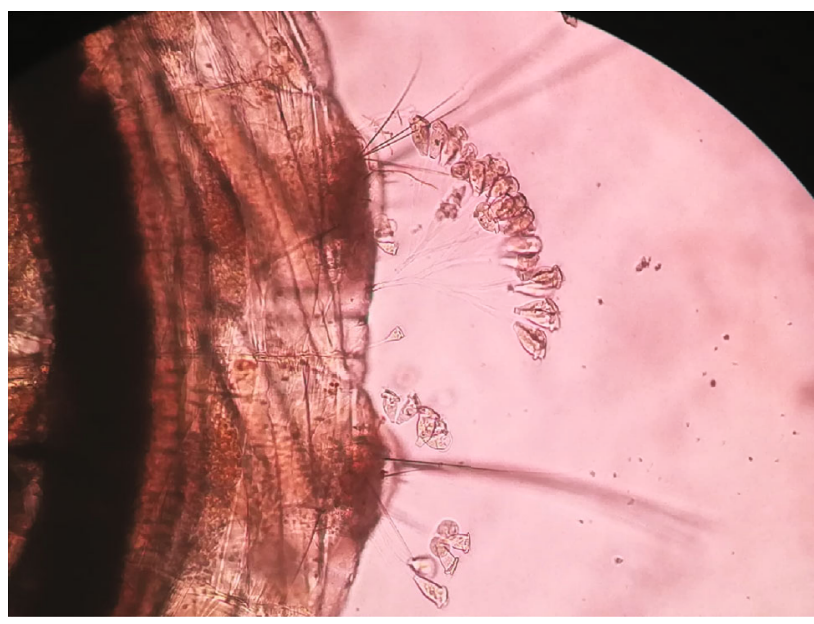

FIGURE 6: Infection of parasite (Zoothamnium sp.) to $3^{\text {rd }}$ larval instars of $C x$. tritaeniorhynchus abdominal region (x100 magnification).

guish it from Vorticella. Vorticella has only a single stalk with one zooid. Upon stimulation, Zoothamnium entire colony contracts into one large globule and then folds the main stalk.

Chilodinella sp. was identified as endoparasitic ciliate causing a pathogenic effect (Figure 7) under natural environmental conditions on $C x$. tritaeniorhynchus mosquito larvae collected from a paddy field $\left(6^{\circ} 57.959^{\prime} \mathrm{N}, 79^{\circ} 59.492^{\prime} \mathrm{E}\right)$. However, considerable mortality was not observed $(4.58 \%$ mortality of larvae compared to controls) due to the infestation of this pathogen to mosquito larvae. Identification was performed by observing the ciliates in wet mounts (Ehrenberg, 1838) (subphylum: Ciliophora: Crytophorida: Chilodonellidae). Endoparasitic ciliates were reported in the host larval body under microscopic observations only.

\section{Discussion}

Endoparasitic ciliate (Protista: Ciliophora), Lambornella stegomyiae, was first reported to infect Aedes albopictus larvae in a sample collected from an earthen pot in Kuala Lumpur [31]. Micks [32,33] reported the lethal effect of the ciliate, 


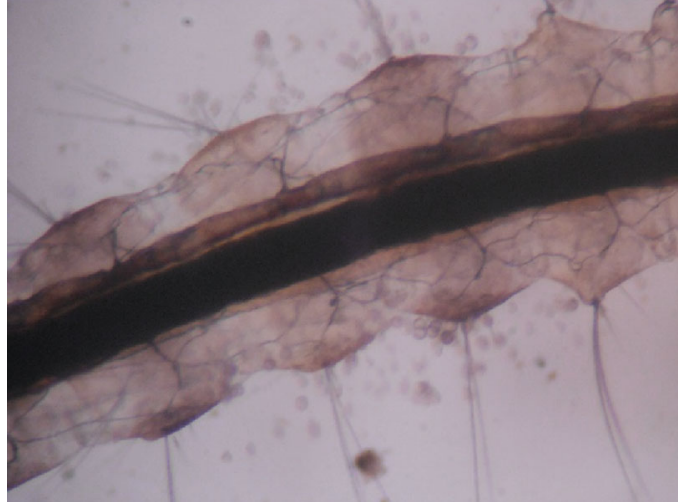

(a)

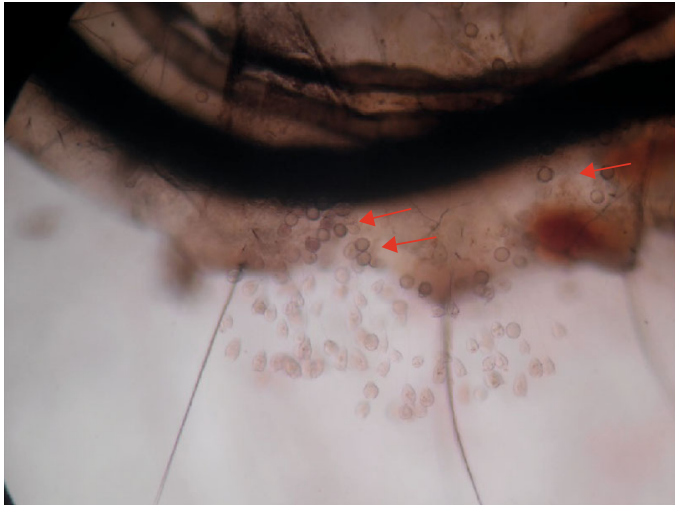

(b)

FIgURE 7: Transparent $C x$. tritaeniorhynchus larva (magnification $\mathrm{x} 40$ ) showing endoparasitic ciliate, Chilodinella, in the host body (a, b); (b) cuticular invasive cysts (arrow marks) of the pathogen on the cuticle of host body (magnification x100).

V. microstoma, on Anopheles quadrimaculatus and An. atroparvus, respectively. Chandrasekar et al. [34] reported that infestation of Vorticella sp. on Anopheles stephensi larvae has caused an inhibition of larval growth, development, and adult emergence. During the present study, Vorticella microstoma, Zoothamnium spp., and Chilodinella sp. were identified as ciliated parasitic or pathogenic species in this study, causing a lethal effect by $V$. microstoma on Culex tritaeniorhynchus, Cx. gelidus, Cx. pseudovishnui, and Cx. quinquefasciatus mosquito larvae. It is important to state that all these ciliates were recorded from paddy/rice field habitats. $V$. microstoma is effective on mainly the paddy field-inhabiting Culex mosquitoes. Numerous shallow pools and irrigation canals built by paddy farmers during seedling transplanting usually serve as ideal breeding sites for mosquito larvae and associated ciliates. Mutero et al. [35] stated that application of nitrogen fertilizer to growing paddy further increases its larval densities. Rainfall alters the physicochemical properties of rice fields, resulting in changes in larval densities and species succession. Once the paddy is harvested in dry condition, abandoned vector-paddy field breeding habitats restrict distribution of parasitic or pathogenic ciliates in the absence of host mosquito larvae. Thus, parasitic agents necessarily undergo a quiescent period to overcome dry spell until the next planting season of paddy coupled with monsoon rains with high vector density situation returns. Thus, the encystation of these ciliates seems a possible way for the time lapse. After excystation, the free-swimming trophont stage of these ciliates could be increased rapidly when the optimum environmental conditions are resumed. Cysts and the process of encystation and excystation have been described in detail for the species, V. microstoma [36] and Chilodinella uncinata ([37]). Even though Chilodinella sp. did not cause considerable mortality in Cx. gelidus mosquito larvae in the present study, Das [37] reported that species $C$. uncinata has caused $25-100 \%$ mortalities in Japanese encephalitis (JE) vector larvae in North India.

The microinvertebrates, namely, Paramecium caudatum, Brachionus forticula, Philodina citrina, Diaphanosoma brachyurum, and Sida crystallina, were recorded in association with mosquito larvae in dried ponds, marshy lands, and irri- gation canals in this study. As reported by Obi et al. (2017), relative abundance of mosquitoes has significantly correlated negatively with those microinvertebrates in rock pools [38]. Garcia-Sánchez et al. [39] reported the presence of three main phyla of algae, Bacillariophyceae, Chlorophyceae, and Cyanobacteria in Aedes aegypti larval habitats in artificial water containers in Girardot, Colombia. Similarly, these algal phyla were reported from both natural and man-made breeding habitats in our study. As reported by Addicott [40] and Blaustein and Chase [1], heterotrophic microeukaryotes such as protists and rotifers in breeding habitats particularly in container habitats are important components of nutritional resources for larvae. Twelve species of rotifers, namely, Lecane lunaris, Keratella tropica, Lecane luna, Lecane papuana, Lepadella ovalis, Monostyla bulla, Notholca acuminata, Pandorina morum, Philodina citrina, Diurella stylata, Euchlanis dilatata, and Brachionus forficula were associated with breeding habitats positive for mosquito larvae. Only one species of cyclopoid copepod, Metacyclops minutus, was recorded with lower occurrence frequency $(0.21 \%)$ from paddy fields in this study. However, M. minutus in this study did not cause any effect in reduction of larval abundance. Several authors reported that cyclopoid copepods act as effective biocontrol agents of mosquito larvae but under the field conditions, the use of crustaceans has become limited during the initial phase of their community development in which their abundance is low [41-43].

Cyanobacteria play an important role as diet items of mosquito larvae. Spirulina major from tree holes, marshy lands, plastic containers, and burrow pits/footprints and Anabaena affinis from irrigation canals were recorded as cyanobacteria species. However, species, namely, Kirchneriella, Scenedesmus, Coelastrum, Selenastrum, Dactylococcus, and Tetrallantos, are virtually indigestible by Culex, Aedes, and Anopheles mosquito larvae, hence causing a reduction of larval survival [41]. Marten [41] reported that mosquito larvae failed to develop successfully in the water where certain species of closely related green algae in the order Chlorococcales are the main source of larval food. Howland [44] has reported that Scenedesmus quadricauda shows no signs of digestion in the mosquito gut. S. quadrimaculatus 
was recorded from ponds $(9.52 \%)$ in the present study with no lethal effect on Ae. albopictus mosquito larvae found from the same habitat. Two more species of Scenedesmus were recorded from this study, namely, S. armatus from blocked drainages and tree holes and S. bijuga from plastic containers, ponds, and paddy fields with no significant effect on mosquito larvae.

\section{Conclusions}

A total number of 45 microbiota species belong to 11 phyla were encountered from different mosquito breeding habitats during the study while the highest percentage abundance was found from phylum Euglenozoa (27.89\%), and species under phylum Amoebozoa (1.22\%) and Sarcodina (1.17\%) had the lowest abundance, and each of its species richness was recorded as one. The majority of the microbiota existed as accidental (abundance $25-50 \%$ of the collections) or rare species (less than $25 \%$ of the collections) in the habitat type according to their abundance. Paddy fields had the highest species richness (17), evenness (23.52), Shannon-Weiner (66.64), and beta diversity (0.65) over 50\% indicating high heterogeneity in microbiota composition among the systems. The autotrophic protists in genera Euglena, Closterium, and Pinnularia served as the diet items to mosquito larvae. Vorticella microstoma, Zoothamnium spp., and Chilodinella sp. were found as possible parasitic and pathogenic agents against mosquito larvae. Vorticella microstoma caused a lethal effect on $C x$. tritaeniorhynchus larvae while $C x$. tritaeniorhynchus, Cx. gelidus, Cx. pseudovishnui, CX. quinquefasciatus, and $C x$. whitmorei mosquito larvae were found to be infected with $V$. microstoma in natural environmental conditions. However, $4.58 \%$ mortality of $C x$. gelidus larvae were observed while no lethal effect of Zoothamnium spp. was found on Cx. tritaeniorhynchus.

\section{Data Availability}

The datasets supporting the conclusions of this article are included in the article.

\section{Conflicts of Interest}

There are no conflicts of interests.

\section{Acknowledgments}

This work was supported by the National Science Foundation of Sri Lanka under the research grant NSF/2017/EB/02.

\section{References}

[1] L. Blaustein and J. M. Chase, "Interactions between mosquito larvae and species that share the same trophic level," Annual Review of Entomology, vol. 52, no. 1, pp. 489-507, 2007.

[2] L. Blaustein, M. Kiflawi, A. Eitam, M. Mangel, and J. E. Cohen, "Oviposition habitat selection in response to risk of predation in temporary pools: mode of detection and consistency across experimental venue," Oecologia, vol. 138, no. 2, pp. 300-305, 2004.
[3] D. Alfonzo, M. E. Grillet, J. Liria, J.-c. Navarro, S. C. Weaver, and R. Barrera, "Ecological characterization of the aquatic habitats of mosquitoes (Diptera: Culicidae) in enzootic foci of Venezuelan equine encephalitis virus in western Venezuela," Journal of Medical Entomology, vol. 42, no. 3, pp. 278-284, 2005.

[4] L. D. Amarasinghe and D. R. Dalpadado, "Vector mosquito diversity and habitat variation in a semi urbanized area of Kelaniya in Sri Lanka," International Journal of Entomological Research, vol. 2, no. 1, pp. 15-21, 2014.

[5] A. N. Nilsson and B. W. Svensson, "Assemblages of dytiscid predators and culicid prey in relation to environmental factors in natural and clear-cut boreal swamp forest pools," Hydrobiologia, vol. 308, no. 3, pp. 183-196, 1995.

[6] M. A. Beketov and M. Liess, "Predation risk perception and food scarcity induce alterations of life-cycle traits of the mosquito Culex pipiens," Ecological Entomology, vol. 32, no. 4, pp. 405-410, 2007.

[7] J. M. Chase and T. M. Knight, "Drought-induced mosquito outbreaks in wetlands," Ecology Letters, vol. 6, no. 11, pp. 1017-1024, 2003.

[8] N. P. Devi and R. K. Jauhari, "Mosquito species associated Within some Western Himalayas Phytogeographic zones in the Garhwal region of India," Journal of Insect Science, vol. 7, no. 32, pp. 1-10, 2007.

[9] A. Mokany and R. Shine, "Biological warfare in the garden pond: tadpoles suppress the growth of mosquito larvae," Ecological Entomology, vol. 28, no. 1, pp. 102-108, 2003.

[10] S. A. Juliano, L. P. Lounibos, and G. F. O’Meara, “A field test for competitive effects of Aedes albopictus on A. aegypti in South Florida: differences between sites of coexistence and exclusion," Oecologia, vol. 139, no. 4, pp. 583-593, 2004.

[11] M. -J. Dole-Olivier, D. M. P. Galassi, P. Marmonier, and M. C. D. Châtelliers, "The biology and ecology of lotic microcrustaceans," Freshwater Biology, vol. 44, no. 1, pp. 63-91, 2000.

[12] R. Knoechel and L. B. Holtby, "Cladoceran filtering rate: body length relationships for bacterial and large algal particles," Limnology and Oceanography, vol. 31, no. 1, pp. 195-199, 1986.

[13] D. D. Williams, The Biology of Temporary Waters, Oxford University Press, USA, 2006.

[14] C. N. B. Bambaradeniya, J. P. Edirisinghe, D. N. De Silva, C. V. S. Gunatilleke, K. B. Ranawana, and S. Wijekoon, "Biodiversity associated with an irrigated rice agro-ecosystem in Sri Lanka," Biodiversity and Conservation, vol. 13, no. 9, pp. 1715-1753, 2004.

[15] R. E. Campos, L. A. Fernandez, and V. E. Sy, "Study of the insects associated with the floodwater mosquito Ochlerotatus albifasciatus (Diptera: Culicidae) and their possible predators in Buenos Aires Province, Argentina," Hydrobiologia, vol. 524, no. 1, pp. 91-102, 2004.

[16] J. M. Glime, "Arthropods: Crustacea-Copepoda and Cladocera," Ecology, vol. 2, pp. 1-10, 2017.

[17] I. Kroeger, M. Liess, and S. Duquesne, “Temporal and spatial habitat preferences and biotic interactions between mosquito larvae and antagonistic crustaceans in the field," Journal of Vector Ecology, vol. 39, no. 1, pp. 103-111, 2014.

[18] L. D. Amarasinghe and H. A. K. Ranasinghe, "Diversity and species composition of microbiota associated with mosquito breeding habitats: a study from Kurunegala district in Sri Lanka," BioMed Research International, vol. 2019, 12 pages, 2019. 
[19] L. D. Amarasinghe and A. R. L. K. Rathnayake, "Prevalence of microfauna associated with different mosquito breeding habitats in a selected area of Sri Lanka," International Journal of Current Microbiology and Applied Sciences, vol. 3, no. 5, pp. 587-598, 2014.

[20] F. P. Amerasinghe, "Illustrated keys to the genera of mosquitoes (Diptera: Culicidae) in Sri Lanka," Journal of the National Science Foundation of Sri Lanka, vol. 23, no. 4, pp. 183-211, 1995.

[21] R. V. Chelliah, "Keys and illustrations to the genera of mosquitoes of Sri Lanka (Diptera: Culicidae)," Contributions of the American Entomological Institute, vol. 7, no. 4, pp. 1-84, 1984.

[22] R. Rattanarithikul, B. A. Harrison, P. Panthusiri, and R. E. Coleman, "Illustrated keys to the mosquitoes of Thailand 1, background; geographic distribution; list of genera, subgenera, and species; and a key to the genera," Southeast Asian Journal of Tropical Medicine and Public Health, vol. 36, no. 1, pp. 1-80, 2005.

[23] B. A. Abeywickrama and L. Abeywickrama, The genera of the freshwater algae of Sri Lanka. Part 1,-UNESCO Man and the Biosphere National Committee for Sri Lanka, Special Publication 6, National Science Council, Sri Lanka, Colombo, 1979.

[24] J. O. Corliss, The Ciliated Protozoa: Characterization, Classification, and Guide to the liteBPrature, Pergamon Press, London, UK, 2nd edition, 1979.

[25] C. H. Fernando and S. R. Weerawardhena, A guide to the freshwater fauna of Ceylon (Sri Lanka), Fisheries Research Station, Ceylon, Sri Lanka, 2002.

[26] E. Lobo and G. Leighton, "Estructuras comunitarias de las fitocenosis planctonicas de los sistemas de desembocaduras de rios y esteros de la zona central de Chile," Journal: Revista de Biologia Marinha, vol. 22, 1986.

[27] S. Harrison, S. J. Ross, and J. H. Lawton, "Beta diversity on geographic gradients in Britain," Journal of Animal Ecology, vol. 61, no. 1, pp. 151-158, 1992.

[28] J. C. Nabout, I. S. de Nogueira, L. G. de Oliveira, and R. R. Morais, "Phytoplankton diversity (alpha, beta, and gamma) from the Araguaia River tropical floodplain lakes (central Brazil)," Hydrobiologia, vol. 575, no. 1, pp. 455-461, 2007.

[29] C. E. Shannon and W. Weaver, The Mathematical Theory of Communication, Illinois University Press, Champaign, IL, USA, 1963.

[30] E. C. Pielou, Ecological Diversity, vol. 1, John Wiley, New York, USA, 1975.

[31] W. A. Lamborn, "A Protozoon pathogenic to mosquito larvae," Parasitology, vol. 13, no. 3, pp. 213-215, 1921.

[32] D. W. Micks, "The lethal effect of the ciliate, Vorticella microstoma Ehrenberg on Anopheles quadrimaculatus larvae," Journal of the National Malaria Society, vol. 9, no. 3, pp. 256-258, 1950.

[33] D. W. Micks, "Vorticella infestation of Anopheles atroparvus Larvae1," Journal of Economic Entomology, vol. 48, no. 2, pp. 215-216, 1955.

[34] D. P. Chandrasekar, P. R. Chandrakant, R. K. Suryawanshi, and S. V. Patil, "Vorticella sp: prospective mosquito biocontrol agent," Journal of Arthropod-Borne Diseases, vol. 10, no. 4, pp. 602-607, 2016.

[35] C. Mutero, P. Ng'ang'a, P. Wekoyela, J. Githure, and F. Konradsen, "Ammonium sulphate fertiliser increases larval populations of Anopheles arabiensis and culicine mosquitoes in rice fields," Acta Tropica, vol. 89, no. 2, pp. 187-192, 2004.
[36] H. E. Finley and A. C. Lewis, "Observations on excystment and encystment ofVorticella microstoma*," Journal of Eukaryotic Microbiology, vol. 7, no. 4, pp. 347-351, 2007.

[37] B. P. Das, "Chilodonella uncinata - a protozoa pathogenic to mosquito larvae," Current Science, vol. 85, no. 4, pp. 483489, 2003.

[38] O. A. Obi, I. H. Nock, and D. A. Adebote, "Biodiversity of microinvertebrates coinhabiting mosquitoes habitats in patchy rock pools on inselbergs within Kaduna State, Nigeria," The Journal of Basic and Applied Zoology, vol. 80, no. 1, pp. 1-12, 2019.

[39] D. C. Garcia-Sánchez, G. A. Pinilla, and J. Quintero, “Ecological characterization of Aedes aegypti larval habitats (Diptera: Culicidae) in artificial water containers in Girardot, Colombia," Journal of Vector Ecology, vol. 42, no. 2, pp. 289-297, 2017.

[40] J. F. Addicott, "Predation and prey community structure: an experimental study of the effect of mosquito larvae on the protozoan communities of pitcher plants," Ecology, vol. 55, no. 3, pp. 475-492, 1974.

[41] G. G. Marten, "Impact of the copepod Meso cyclops Leuckarti pilosa and the green alga Kirchneriella irregularis upon larval Aedes albopictus (Dip-tera: Culicidae)," Bulletin of the Society for Vector Ecology, vol. 9, no. 1, pp. 1-5, 1984.

[42] G. G. Marten, "Evaluation of cyclopoid copepods for Aedes albopictus control in tires," Journal of the American Mosquito Control Association, vol. 6, pp. 681-688, 1990.

[43] F. Riviere, B. H. Kay, J. M. Klein, and Y. Sechan, "Mesocyclops aspericornis (Copepoda) and Bacillus thuringiensis var israelensis for the biological control of Aedes and Culex vectors (Diptera: Culicidae) breeding in crab holes, tree holes and artificial containers," Journal of Medical Entomology, vol. 24, no. 4, pp. 425-430, 1987.

[44] L. J. Howland, "The nutrition of mosquito larvae with special reference to their algal food," Bulletin of Entomological Research, vol. 21, no. 4, pp. 431-439, 1930. 